\title{
EFFORT WITH DETERMINATION INFLUENCE RESULTS! PARENT'S PARTICIPATION IN PHYSIOTHERAPY TREATMENT SESSIONS FOR CHILDREN WITH SENSORY PROCESSING DISORDER - AN INTER- ESTING CASE REPORT
}

\author{
Hulsha Paudyal *1, Dhanesh Kumar KV ${ }^{2}$.
}

*1 Postgraduate, NITTE Institute of Physiotherapy, Mangalore, Karnataka, India.

2 Professor and Principal, NITTE Institute of Physiotherapy, Mangalore, Karnataka, India.

\section{ABSTRACT}

Background: Sensory processing disorder, (SPD) is a condition that exists when sensory signals do not get organized into appropriate responses. The relationship between mind and behavior is altered.

Case Report: 15 years old- girl diagnosed clinically as SPD, who underwent eight weeks of physical therapy rehabilitation which included counseling to the caregiver for their active participation in the treatment, behavioral modification, and physical therapy. A sensory profile was used as an outcome measure. Sensory profile caregiver questionnaire was taken on day 1 , at the end of 4 th week, and at the end of 8th week.

Result: Documented improvements in auditory, visual, activity level, body position, movement touch and emotional/social components of the Sensory profile were noted.

Conclusion: Rehabilitation with the active involvement of parents improves the children with SPD.

KEY WORDS: Sensory processing disorder, children, exercise, parents, sensory profile, physical therapy, Behavior modification.

Address for correspondence: Hulsha Paudyal, Postgraduate, NITTE Institute of Physiotherapy,

Mangalore, Karnataka, India. E-Mail: hulshap@gmail.com

Access this Article online

Quick Response code

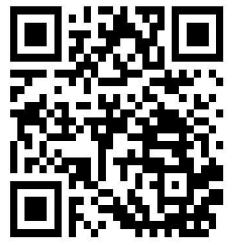

DOI: $10.16965 /$ ijpr.2018.187

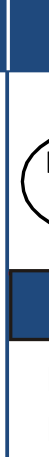

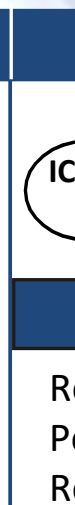


the behavior shown by the individual. Some individuals may not be able to perceive the sensations by birth which will be more pronounced when milestones are altered. When a child on becoming a toddler, should be able to understand the basic pragmatic language and should be able to utter a few words in response to the command. If he/she is not able to concentrate, nor paying attention, or having difficulty in pronouncing, with or without hyperactive behavior, having trouble in perceiving the first sensations, etc., are termed to be sensory processing disordered children. The critical difficulties observed in SPD children in day to day life such as brushing, eating, dressing, toiling, bathing, and other leisure activities. Because of which both gross and fine motor skills get delayed. Literature suggests both genetic and environmental causes as prerequisite factors for SPD. Children are born for exploring the environment in their early age. If they are limited by the fact that their own body is not supporting their development, this may hamper their future regarding their family, social and professional life [7].

Untreated SPD can affect the successful life. Assessment and appropriate age-matched management play a vital role in the development of the child. Literature can be retrieved in the management of SPD children employing occupational therapy through Sensory Integration, behavioral modification, and functional ADL training. There is paucity in the literature which can be retrieved on the role of physiotherapy in the treatment of children with SPD. Physiotherapy helps in managing sensory-based motor issues which include both fine and gross motor activities. However, as paucity exists in the literature, there is a necessity to know its effectiveness. Treatment can be successful only when the parents can understand the sessions and actively involve themselves in the rehabilitation of their child, as a home program is equally important as institutionalized rehabilitation. This case report aims to explain the role of parents and physical therapist in the treatment sessions of children with SPD for effective management.

\section{CASE REPORT}

We report a female child of 15 years-old diag- nosed with SPD. Mother of the child approached our Physiotherapy OPD, along with her child. Initially, the assessment was taken focusing more on fine and gross motor activities. Child's ADL's history was taken from mother, and the child was observed for various transitions. The child presented as self-preserved, not interactive with surroundings, no active participation, and getting diverted easily, difficulty in moving limbs freely, difficulty in moving fast with a fear of fall, struggle to move on a swing, difficulty in writing and prehension activities [8].

There was no restriction in range of motion, but control was inadequate. As mother was not actively involving herself, neither in the assessment nor management we faced a diagnostic challenge. Once we counseled mother and took her help, we were able to assess and diagnose child condition. To determine the child's' present state and quantify the prognosis sensory profile[9] caregiver questionnaire was used along with physical assessment. An opinion of the clinical psychologist was taken to gain clarity on the problem faced by the child, and we diagnosed her as Sensory processing disordered child. As there was no provision for the parents to approach an occupational therapist they continued treatment with us. As we found it to be an appealing case we took an informed consent from mother and explained about the importance of therapy and asked her to involve in the sessions actively. The treatment was planned for eight weeks spanning between February 2018-April 2018.

Fig. 1: Therapist and child playing with ball.

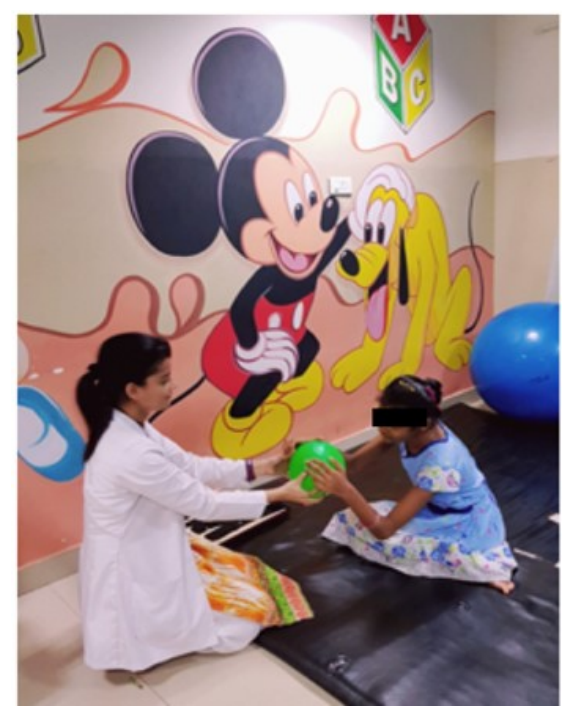


Fig. 2: Prehension training.

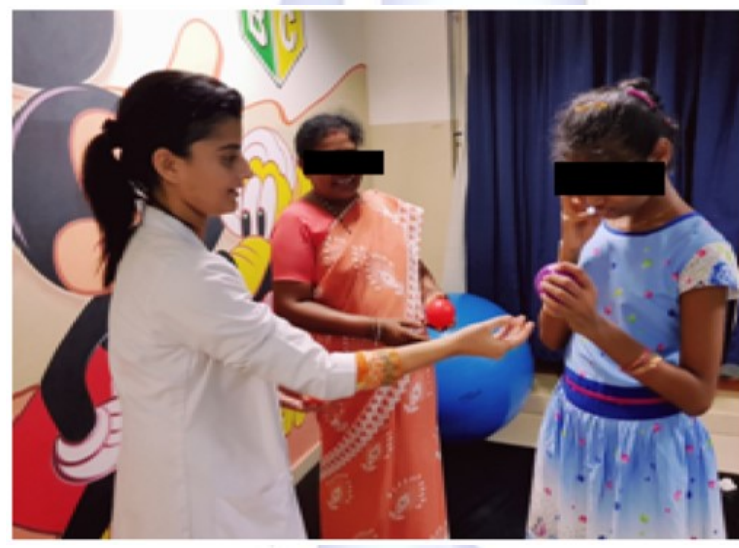

Fig. 4: writing.

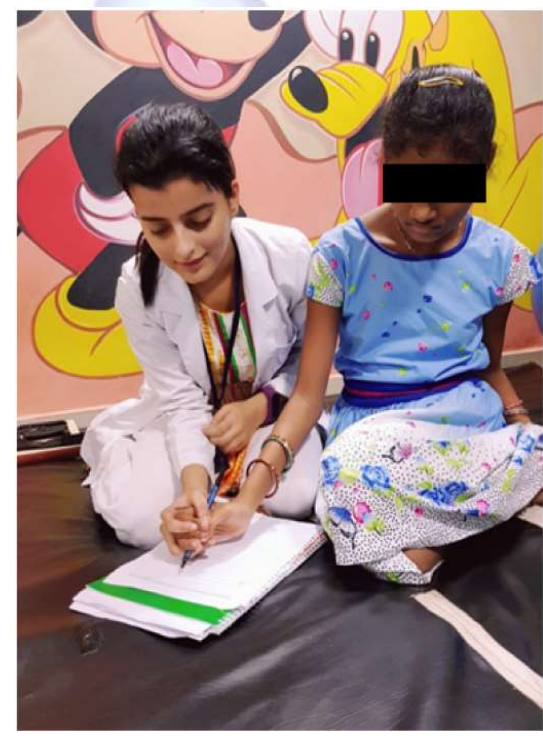

Graph 1: Illustration of the sensory profile.

Sensory Profile

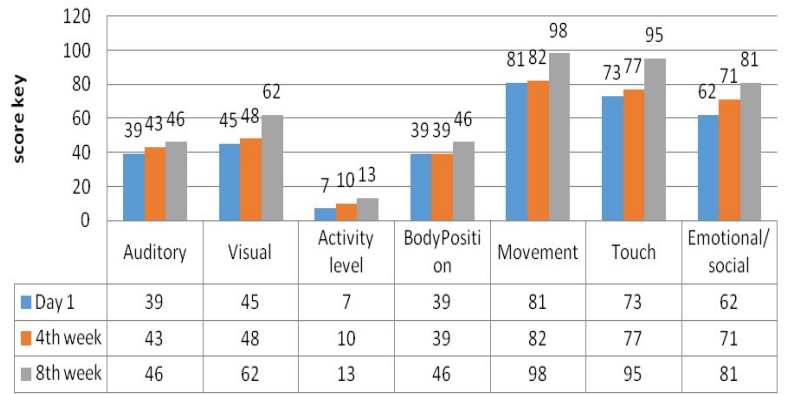

Graph 2: Illustration of sensory profile regarding high and low frequency.

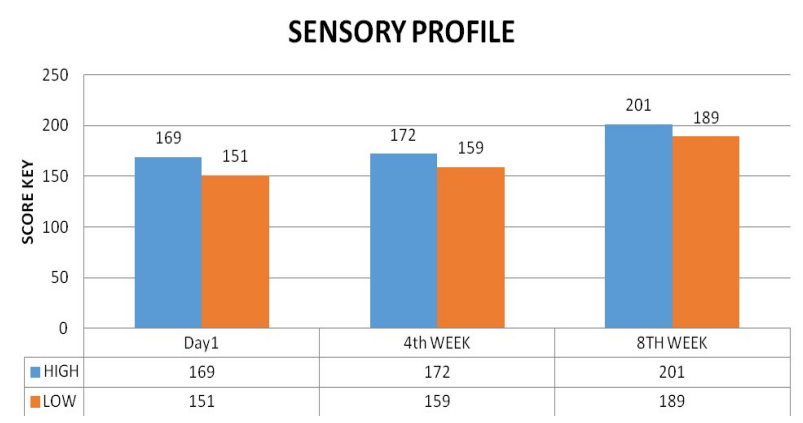

\section{METHODOLOGY}

The initial physiotherapy goals were set to be the child, and parent counseling, Both parent and physical therapist were involved in the sessions of the child to accomplish the goal of active involvement of the child in ADL's. Group therapy with the passing ball, peer interaction, introducing with other children was initiated where the child took a long time to be interactive and had a fear of mother. So, the mother was counseled for the same. The intervention continued for 1 hour a session, three sessions per week for eight weeks. For each session, the mother was given counseling, and the daily habits of the child were noted. The child started to get diverted easily because of noise made by other children, so one to one sessions were started where the child looked around and began to search for mother, the mother was counseled for the same, and we brought her back to the sessions. The child was entirely dependent on the mother for ADL. Fine motor training was initiated, the mother was asked to perform activities (brushing, writing, combing, buttoning, dressing) in-front of the child at home as a home programme [10].

Slowly mother was wholly involved in the sessions and child was also comfortable. For fine motor activities, hand rehabilitation was initiated. The child was interested and happy, handling the cylindrical grips among all the grips and was able to use prehensions easily on repeated practice. The sensory profile [9] was recorded on day one, at the end of 4th week and after 8th week to document the progression which is given in graphs (1\&2) illustrated below. Documented improvement in sensory profile was noted. The involvement of mother helped in maintaining continuity of sessions for 
eight weeks. Throughout the treatment period of eight weeks, there was no adverse or unanticipated event. We used CARE checklist (2013) for writing this case report.

\section{RESULTS AND DISCUSSION}

During the treatment Sensory Profile was taken on day 1 , end of the 4th week and at the end of 8 th week. There was a tremendous improvement in auditory, visual, activity level, body position, movement touch and emotional/social components of Sensory Profile which is shown in Graphs (1\&2). The improvements in auditory, visual, emotional/social and activity level are primarily because of child peer play and involving mother in the treatment sessions. The child was given the freedom to choose and complete the task herself, which added success in our physiotherapy session. Cooperation from the mother in maintaining the change at home by the proper home program was helpful in getting the child's active participation[3]. We know the fact that we cannot completely reverse the cause, but we focused on maintaining and improving active and functional movements of the child relevant to the situational demand within limits. Frequent reassessments during treatment through the sensory profile and physical assessment helped us in solving the problems and attaining the goal. Although we reached minute goals in 8 weeks, we believe if we follow this goal- directed, problem-solving physiotherapy protocol we can achieve further improvement in the child as we are planning for a follow-up study to see the carry-over effect of the given treatment.

\section{CONCLUSION}

Sensory processing disorder, (SPD) is a condition that exists when sensory signals do not get organized into appropriate responses, [1] .

Our case report has documented treatment can be successful only when the parents can understand the sessions and actively involve themselves in the rehabilitation of their child, as the home program is equally important as institutionalized rehabilitation.

\section{ABBREVIATION}

ADL - Activity of Daily Living. SSPD - Sensory Processing Disorder.
SI - Sensory integration.

OPD - Out Patient Department.

\section{ACKNOWLEDGEMENTS}

We are very grateful for the support provided by Dr. Purusotham Chippala, Clinical in charge, Department of Physiotherapy, Justice K S Hegde Charitable Hospital, Deralakatte, Mangalore, India. Sincere thanks to Mr. Rakesh Krishna for his consistent encouragement.

Informed Consent: Informed consent was taken from the mother of the child before the beginning of the treatment sessions.

\section{Conflicts of interest: None}

\section{REFERENCES}

[1]. Ayres, A. J. (1979). Sensory integration and the child: Understanding hidden sensory challenges. Los Angeles: Western Psychological Services.

[2]. Sensory Integration Therapies for Children With Developmental and Behavioral Disorders. PEDIATRICS. 2012;129(6):1186-1189.

[3]. Sealy J, Glovinsky I. Strengthening the reflective functioning capacities of parents who have a child with a neurodevelopmental disability through a brief, relationship-focused intervention. Infant Mental Health Journal. 2016;37(2):115-124.

[4]. Bundy A. Sensory integration. Philadelphia: F A Davis; 2015

[5]. Bar-Shalita T, Vatine J, Parush S. Sensory modulation disorder: a risk factor for participation in daily life activities. Developmental Medicine \& Child Neurology. 2008;50(12):932-937.

[6]. Dunn W. The Sensations of Everyday Life: Empirical, Theoretical, and Pragmatic Considerations. American Journal of Occupational Therapy. 2001;55(6):608-620.

[7]. Cosbey J, Johnston S, Dunn M. Sensory Processing Disorders and Social Participation. American Journal of Occupational Therapy. 2010;64(3):462-473.

[8]. Bundy A, Shia S, Qi L, Miller L. How Does Sensory Processing Dysfunction Affect Play?. American Journal of Occupational Therapy. 2007;61(2):201-208.

[9]. Dunn W. The Sensory Profile: User's Manual. San Antonio: The Psychological Corporation; (1999).

[10]. Liao S, Hwang Y, Chen Y, Lee P, Chen S, Lin L. Homebased DIR/Floortime ${ }^{\mathrm{TM}}$ Intervention Program for Preschool Children with Autism Spectrum Disorders: Preliminary Findings. Physical \& Occupational Therapy In Pediatrics. 2014;34(4):356-367.

How to cite this article: Hulsha Paudyal, Dhanesh Kumar KV. Effort with determination influence Results! Parent's Participation in Physiotherapy treatment sessions for Children with Sensory Processing Disorder - An interesting Case Report. Int J Physiother Res 2018;6(6):2936-2939. DOI: 10.16965/ijpr.2018.187 